\title{
O ensino de Química para alunos surdos: uma Revisão Sistemática
}

\author{
Chemistry teaching for deaf students: a Sistematic Review
}

La enseñanza de Química para alumnos sordos: una Revisión Sistemática

\section{* Greice de Souza Vertuan}

Doutoranda pela Universidade Federal de São Carlos, São Carlos, São Paulo, Brasil. greicevertuan@hotmail.com

\section{** Lara Ferreira dos Santos}

Professora doutora da Universidade Federal de São Carlos, São Carlos, São Paulo, Brasil. larasantos.ufscar@gmail.com

Recebido: 21 de fevereito de 2018

Aprovado: 16 de novembro de 2018

\section{RESUMO}

Pessoas com deficiência tem sido tema de diversas discussões nas mais variadas áreas, visto que as Leis que garantem direitos e deveres a este público são recentes. Assim, o objetivo desta pesquisa foi realizar uma revisão sistemática em bases de dados online que permitiram identificar, categorizar e analisar os trabalhos já realizados com alunos surdos no ensino de Química após a criação da Lei o 10.436 em 2002. A busca dos trabalhos foi feita na base de dados Portal de Periódicos da CAPES a partir da combinação de sete descritores resultando finalmente em 8 trabalhos pertinentes ao tema. Após a análise dos trabalhos encontrados observou-se que há poucas pesquisas na área, sendo necessário um maior aprofundamento de pesquisas na área de ensino de química para surdos, bem como conhecimento da Libras pelos profissionais da área da educação.

Palavras-chave: Educação Especial; Surdez; Ensino de química.

\section{ABSTRACT}

People with disabilities have been the subject of several discussions in the most varied areas, since the Laws that guarantee rights and duties to this public are recent. Thus, there search objetctive was to carry out a systematic review of online databases that allowed to identify, categorize and analyze the Works already done with deaf students at the Chemistry teaching after the creation of Law 10.436 in 2002. The search for the Works was done in database Portal de Periódicos da CAPES from the combination of seven descriptors resulting finally in 8 works pertinente to the theme. After analyzing the studies, it was observed that there are few researches in this area, requiring a greater depth of research in the area of teaching chemistry for deaf, as well as knowledge of Libras by professionals in education area.

Keywords: Special Education; Deafness; ChemistryTeaching. 


\section{RESUMEN}

Las personas con discapacidad ha sido tema de diversas discusiones en las más variadas áreas, ya que las Leyes que garantizan derechos y deberes a este público son recientes. Así, el objetivo de esta investigación fue realizar una revisión sistemática en bases de datos online que permitieron identificar, categorizar y analizar los trabajos ya realizados con alumnos sordos en la enseñanza de Química tras la creación de la Ley no 10.436 en 2002. La búsqueda de los trabajos fue hecha en la base de datos Portal de Periódicos da CAPES a partir de la combinación de siete descriptores resultando finalmente en 8 trabajos pertinentes al tema. Después del análisis de los trabajos encontrados se observó que hay pocas investigaciones en el área, siendo necesario una mayor profundización de investigaciones en el área de enseñanza de química para sordos, así como conocimiento de la Libras por los profesionales del área de la educación.

Palabras clave: Educación Especial; sordera; Enseñanza de química.

\section{Introdução}

As concepções sobre a surdez têm se afastado cada vez mais das abordagens clínicas e se aproximado de pressupostos socioantropológicos, visando uma melhor compreensão dos desafios postos nos diversos espaços sociais e, especialmente, no âmbito educacional. É importante compreender que a educação deve se aproximar das concepções culturais e sociais dos indivíduos. Para Skliar (1998), a educação de surdos e a surdez não podem mais ser discutidas sob o pressuposto de um desvio da normalidade, negando a construção da identidade surda pelas relações construídas entre outros surdos, sua língua visuogestual, cultura e história. O referido autor defende que "[...] o fato de que os surdos também possam ser considerados através da diferença não implica igualar suas diferenças às de outros grupos para, posteriormente, normalizar o contexto histórico e cultural de sua origem" (SKLIAR, 1998, p. 45).

Em uma concepção socioantropológica, o autor discute a educação bilíngue considerando a identidade surda para a construção de um modelo pedagógico apropriado para o desenvolvimento deste indivíduo, respeitando sua cultura, promovendo o uso da língua de sinais e dando significado a uma segunda língua na educação dos surdos. $\mathrm{O}$ referido autor (SKLIAR, 1998) também trata sobre a importância da participação da comunidade surda neste debate, o que pode contribuir com as questões educacionais, proporcionando iguais condições e oportunidades, respeitando as especificidades do indivíduo e da sua língua.

No ano de 2002, foi publicada a Lei 10.436 que reconhece a Língua Brasileira de Sinais - Libras - como meio legal de comunicação e expressão das comunidades surdas 
http://dx.doi.org/10.5902/1984686X31242

brasileiras (BRASIL, 2002). Em seguida, no ano de 2005, com a divulgação do Decreto 5.626 (BRASIL, 2005), as questões educacionais passaram a ser discutidas; para além do uso da Libras, passou-se a discutir a educação bilíngue para surdos, além da formação de profissionais específicos para atendimento a esta clientela, como o professor bilíngue, o professor de Libras e o Tradutor e Intérprete de Libras-Língua Portuguesa, também denominado por Tradutor e Intérprete de Língua de Sinais (TILS), como traz o Capítulo VI:

Art. 22. As instituições federais de ensino responsáveis pela educação básica devem garantir a inclusão de alunos surdos ou com deficiência auditiva, por meio da organização de:

I - escolas e classes de educação bilíngue, abertas a alunos surdos e ouvintes, com professores bilíngues, na educação infantil e nos anos iniciais do ensino fundamental;

II - escolas bilíngues ou escolas comuns da rede regular de ensino, abertas a alunos surdos e ouvintes, para os anos finais do ensino fundamental, ensino médio ou educação profissional, com docentes das diferentes áreas do conhecimento, cientes da singularidade linguística dos alunos surdos, bem como com a presença de tradutores e intérpretes de Libras - Língua Portuguesa (BRASIL, 2005).

O referido Decreto garante o direito à educação dos surdos mediante sua singularidade linguística. Com relação aos anos finais do ensino fundamental, tema do presente estudo, o documento destaca a necessidade da presença do TILS em sala de aula, bem como no Ensino Médio e Profissional. Além disso, o aluno surdo deve ter acesso ao AEE (Atendimento Educacional Especializado) em turno diferente ao da escolarização regular e uso da tecnologia para o desenvolvimento da complementação curricular (BRASIL, 2005). O que é proposto pelo Decreto é fundamental para garantir acesso, permanência e desenvolvimento do surdo no espaço escolar, respeitando o uso de sua língua - a Libras -, como primeira língua, e sua constituição como sujeito.

$\mathrm{Na}$ educação, especificamente no Ensino Médio de uma escola regular, no processo de ensino e aprendizagem de um aluno surdo a comunicação deve ser mediada pelo TILS (BRASIL, 2005). A formação desse profissional "[...] deve efetivar-se por meio de curso superior de Tradução e Interpretação, com habilitação em Libras - Língua Portuguesa." (BRASIL, 2005, artigo 17). Entretanto, em lei posterior ao Decreto, quando do reconhecimento da profissão por meio da lei 12.319 (BRASIL, 2010), nota-se uma alteração quanto à formação exigida para a atuação profissional, que passa a ser em nível médio.

Embora o TILS seja o profissional responsável por transformar a mensagem da Libras para o português e vice-versa, esta mediação torna-se de extrema relevância, se considerarmos que tal profissional tem formação generalista (LACERDA; GURGEL, 2011) e que deve atender às mais diversas demandas - especialmente no espaço educacional. 
http://dx.doi.org/10.5902/1984686X31242

Além disso, nota-se uma escassez de vocabulário em Libras para as diferentes áreas de conhecimento, considerando que "ainda são relativamente poucas as iniciativas de elaboração de repertórios para áreas de especialidades" (OLIVEIRA; STUMPF, 2013, p. 221). Deve-se questionar, deste modo, que fatores levaram a esta alteração legal do prérequisito de formação do profissional, sabendo-se das especificidades de seu trabalho e da necessidade de conhecimentos aprofundados nas mais diversas áreas de conhecimento.

Mesmo com toda a legislação vigente, é possível afirmar que somente a presença do TILS em sala de aula é insuficiente para garantir o sucesso dos processos de ensino e aprendizagem aos surdos. Há diversos fatores que influenciam tais processos, como: a insuficiente oferta de TILS no mercado de trabalho; a falta de formação adequada dos TILS para o trabalho no âmbito educacional; o desconhecimento da existência da língua de sinais pelo professor; a não adaptação de aspectos didáticos e metodológicos para o público surdo. Esses fatores proporcionam uma inclusão educacional pouco satisfatória para o aluno surdo numa sala de aula regular, pois o processo de ensino e aprendizagem não se faz somente com os conteúdos das disciplinas, mas também com a interação e comunicação com o outro (CAMPOS, 2014; LACERDA, 2006). Assim, em um modelo educacional inclusivo, para que o surdo seja atendido em suas necessidades é preciso que, dentre outros aspectos, o professor e os TILS sejam parceiros de atuação e que as aulas sejam melhor estruturadas

A Libras é uma língua de modalidade visuogestual e de extrema importância cultural para o surdo, pois é por meio desta que será constituída a linguagem, a cultura surda e a socialização do indivíduo. Sendo assim, espera-se que a primeira língua (L1) a qual o surdo tenha contato e se aproprie, para a comunicação e acesso aos conhecimentos, seja a Libras e que, posteriormente, torne-se letrado, ou seja, que possa desenvolver a Língua Portuguesa em sua modalidade escrita (L2) - língua esta que perpassa todo o aprendizado escolar e, portanto, necessita ser ensinada de forma diferenciada ao aluno surdo. Assim, deve haver uma relação entre signo e significação estabelecida entre as línguas, que possa auxiliar o surdo na compreensão da língua portuguesa na modalidade escrita como L2, respeitando-se os aspectos socioculturais do indivíduo e da língua de sinais (LODI, 2005; 2013).

Pensando em como se dá o processo de ensino e aprendizagem do aluno surdo, visto que se trata de outra forma de comunicação (visuogestual), podemos associar o que Moraes e Galiazzi (2006, p. 2) trazem sobre a mediação do conhecimento: "a apropriação 
http://dx.doi.org/10.5902/1984686X31242

das palavras de outras vozes para compreender melhor o texto". Então, o TILS é quem "dará voz" e possibilitará a interpretação/compreensão do conceito científico a ser explanado pelo professor em aula, do português para a Libras. Neste contexto, o TILS é um mediador fundamental, pois ele é responsável pela escolha dos sentidos mais adequados durante a interpretação, visto que, por vezes, é necessário o uso de sinônimos ou analogias para a explicação de um conceito científico, tal como é realizado usando a língua portuguesa. Lacerda, Santos e Caetano (2014) enunciam sobre a importância da parceria do TILS e do professor quando não há sinais convencionados para algum conceito específico. Neste caso, o TILS pode apresentar a palavra ao surdo usando datilologia (soletração do alfabeto manual) ou mesmo uma imagem que represente o conceito e, após a explanação deste em Libras, aluno e TILS podem elaborar um sinal que exemplifique 0 conceito e facilite o processo de tradução/interpretação e compreensão do conteúdo.

O sistema educacional, de modo geral, está voltado à língua dominante (majoritária), o que leva o professor a preparar a aula de modo prioritariamente textual para os alunos ouvintes. O professor não se atenta para a potencialidade da língua de sinais e o que esta pode proporcionar para a apresentação de conceitos para o aluno surdo. É relevante que o professor ao preparar suas aulas pense numa maneira de atender pedagogicamente às necessidades educacionais destes alunos surdos com a parceria do TILS, pois os conceitos devem ser organizados na língua de sinais, fazendo uso de recursos visuais que favoreçam a elaboração conceitual, como imagens, desenhos, vídeos legendados, mapas conceituais - e outros materiais que podem auxiliar a explanação do conteúdo. (LACERDA; SANTOS; CAETANO, 2014).

De acordo com Vigotski (1991) a aquisição de conceitos é fundamental para o desenvolvimento do indíviduo (surdo ou não surdo) e a escola tem papel de grande relevância para que conceitos formais/científicos sejam apropriados pelas crianças e adolescentes inseridos neste espaço. Os processos mentais que resultam na formação de conceitos têm início na infância, mas se estendem até a adolescência, quando os conhecimentos vão se transformando e se consolidando. É na/pela escola que conceitos cotidianos adquirem novos sentidos e se transformam em conhecimentos novos e mais elevados, pela mediação do professor e na relação com os outros que desse processo participam. Os estudos de Vigostki apontam que duas funções mentais superiores são indispensáveis no processo de construção dos conhecimentos e conceitos: a percepção e a linguagem. 
Voltando-nos ao tema deste estudo, deparamo-nos com uma questão bastante complexa; nem sempre o aluno surdo inserido no espaço escolar apresenta a linguagem desenvolvida de modo a possibilitar a construção de conceitos nas diferentes áreas de conhecimento. A falta de acesso à Libras de forma precoce mostra-se um empecilho ao desenvolvimento de linguagem deste aluno, bem como a forma como esta língua está presente no ambiente escolar. Assim, compreendemos que o domínio da língua usada para a comunicação permitirá que o indivíduo perpasse o caminho do senso comum para a inserção e compreensão do conhecimento científico durante as aulas (BIZZO, 2002). Para Mortimer (1996, p. 5) é necessário que haja uma transformação na forma de agir e pensar do aluno, pois "[...] aprender ciências envolve a iniciação dos estudantes em uma nova maneira de pensar e explicar o mundo natural, que é fundamentalmente diferente daquelas disponíveis no senso comum". Assim, em consonância com os pressupostos de Vigostki, compreende-se que para que haja generalização, apropriação de conceitos científicos e abstração é necessário que o indivíduo tenha a linguagem preservada e uma língua constituída, que permitam o acesso aos conhecimentos. A língua de sinais, deste modo, precisa estar presente de modo efetivo no ambiente escolar, possibilitando a exploração de tais conceitos; para que isto ocorra é necessária a presença de educadores (surdos e ouvintes) com fluência e competência na Libras (SANTOS, 2007). Deste modo, o aluno terá condições equânimes às do aluno ouvinte para acompanhar os diversos conteúdos que circulam em sala de aula, especialmente nos anos finais do ensino fundamental e ensino médio.

De acordo com as Orientações Curriculares para o Ensino Médio (MEC, 2006), o Ensino Médio é o período em que os alunos, adolescentes, mostram-se plenamente capacitados para os processos de abstração e conscientes do próprio conhecimento. Deste modo, estando aptos ao aprendizado de conteúdos e conceitos mais aprofundados (em quantidade e qualidade), destaca-se nesta etapa educacional a área de Ciências da Natureza, Matemática e suas tecnologias, com ênfase especialmente nos componentes curriculares Física, Biologia, Matemática e Química - sendo este último nosso objeto de estudo.

A Química, como um dos conteúdos específicos do Ensino Médio, tem como objetivo abordar questões do cotidiano do aluno, com a perspectiva de que este seja capaz de compreender as transformações do mundo em que vive, e que ainda possa posicionar-se e argumentar sobre temas e situações sociais que envolvem a Química. Para isto, é 
http://dx.doi.org/10.5902/1984686X31242

importante que o aluno esteja bem informado, bem fundamentado e consciente do seu papel na sociedade (BNCC, 2016). Em uma reflexão sobre o motivo de se ensinar Química, enfoque deste estudo, Chassot (1993, p. 39) afirma que "a Química também é uma linguagem(...). Assim, o ensino de Química deve ser um facilitador da leitura do mundo". Este ensino irá permitir que o aluno possa interagir e trabalhar com o conhecimento construído, tornando-se um cidadão questionador, consciente de seu papel na sociedade e capaz de transformar o mundo. Para que isto aconteça é necessário que o que se aprende na escola faça sentido na vida deste aluno, que o professor saiba educar através da Química, que o conteúdo a ser ensinado seja algo do cotidiano. Só assim o aluno poderá transformar o senso comum que traz consigo em saberes científicos e significativos para si.

Pensando no processo de ensino e aprendizagem e na educação de alunos surdos realizada em salas de aula regulares, Novaes e Trugillo (2011) discutem sobre a falta de profissionais com formação adequada para atuar na área da Educação Especial (TILS e professores), falta de estrutura e recursos na instituição de ensino, evidenciando a carência de preparo para receber este aluno e incluí-lo, independentemente de sua deficiência. Esta falta de preparo dos professores para lidar com as especificidades da surdez está presente nas diversas áreas da educação do ensino básico, visto que poucos professores têm formação específica para tal ou pouco conhecem a Libras. É importante que o professor se envolva com as questões da surdez e repense no conteúdo a ser ministrado em aula, trazendo aspectos e recursos visuais para que o aluno possa construir e compreender os conceitos abordados em aula (SANTOS; LACERDA, 2015).

No trabalho desenvolvido por Sales, Penteado e Moura (2015), por meio de uma pesquisa colaborativa desenvolvida nas aulas de matemática, os sinais de um determinado conceito que não eram encontrados em livros ou dicionários de Libras eram negociados entre professor, TILS e alunos, de acordo com a compreensão dos conceitos matemáticos em questão e a ampliação da língua no campo lexical, evidenciando a importância da parceria entre TILS e professores para tornar os conceitos acessíveis em Libras para o aluno surdo. Com relação a algumas disciplinas, como é o caso da química, foco deste estudo, os conteúdos são demasiadamente abstratos e exigem do docente maior flexibilidade para que todos os alunos possam ter compreensão dos conceitos. A valorização de aspectos visuais de determinados conteúdos pode trazer resultados positivos para alunos surdos e não surdos e a parceria em sala de aula (professor-TILS) 
possibilita o acesso aos conteúdos ao aluno surdo no processo de ensino e aprendizagem - mas isso requer uma mudança de postura do professor quanto à metodologia e estratégias didáticas.

Os trabalhos referidos demonstram que a Libras, assim como toda língua, está em constante processo evolutivo, pois isto ocorre de acordo com a necessidade e demanda de seus usuários. O indivíduo surdo vem conquistando aos poucos as instâncias superiores de ensino (Médio, Superior e pós-Graduação) e são estas conquistas que têm motivado a necessidade da ampliação da língua e criação léxico específico para as diferentes disciplinas e termos técnicos (CAETANO; LACERDA, 2014). As autoras ainda sugerem que TILS e professores bilíngues com boa formação favorecem a aquisição de conceitos bem explicados e não somente a correlação de uma determinada palavra em português para um sinal na Libras, pois somente o sinal sem o conceito adequado não contribui para o processo de ensino e aprendizagem do indivíduo surdo.

Diante desta problemática questiona-se o que tem sido produzido - seja em recursos didáticos/pedagógicos, seja em formação de recursos humanos - para alunos surdos na disciplina de Química em salas de aula regulares. Assim, o objetivo desta pesquisa foi realizar uma revisão sistemática de artigos científicos com enfoque no ensino de Química para alunos surdos, recursos didáticos/pedagógicos e formação de recursos humanos a ela associados, e seus usos em salas de aula com alunos surdos. O período determinado para a busca será após a publicação da Lei de Libras, pois se espera que a educação tenha se modificado em relação ao atendimento educacional da pessoa surda a partir desse momento.

\section{Metodologia}

O presente estudo consistiu em uma revisão sistemática (GIL, 2008; COSTA; ZOLTOWSKI, 2014) dos trabalhos científicos disponíveis em bases de dados digitais, descrevendo a temática proposta e fazendo uma análise crítica e reflexiva do material encontrado. O material foi selecionado através da base de dados: Portal de Periódicos da Capes.

A opção por este tipo de trabalho deveu-se ao intuito de identificar, categorizar e refletir sobre o que tem sido apresentado nos trabalhos que abordam a surdez no âmbito da educação básica, na disciplina de Química, após a deliberação da Lei que reconhece a Libras (BRASIL, 2002) como meio de comunicação do indivíduo surdo. O trabalho foi 
http://dx.doi.org/10.5902/1984686X31242

norteado pelas seguintes etapas: escolha da temática, critérios de inclusão e exclusão da amostra para busca dos artigos, procedimentos de coleta de dados, estratégia de avaliação e análise de dados (GALVÃO; SAWADA; TREVISAN, 2004). Os trabalhos foram selecionados e analisados por dois pesquisadores, sendo eles os autores do presente estudo.

Os descritores usados para a busca foram: surdez, surdo, educação inclusiva, Libras, química, usando os operadores lógicos "AND" e "OR" para a combinação das palavraschave, e o descritor: língua de sinais, individualmente, gerando 7 possibilidades de busca (Figura 1). Os trabalhos foram selecionados a partir da ferramenta de busca da biblioteca virtual da CAPES/Periódico. O critério de seleção incluiu artigos, com texto online acessível na íntegra (devido à maior circulação e atualização), em língua portuguesa, durante o período de 2002 a 2017 - período de 15 anos da publicação da Lei da Libras, além de abordar a surdez e o ensino de química. Os critérios de exclusão foram: publicações que não se tratavam de artigos, publicações incompletas ou indisponíveis, artigos repetidos e que não tratavam do tema proposto pela revisão. As publicações foram selecionadas após a leitura do título e do resumo das mesmas, e que atendessem aos objetivos propostos por este estudo (PEREIRA et al, 2016).

Figura 1 - Síntese do procedimento para obtenção da amostra da revisão sistemática

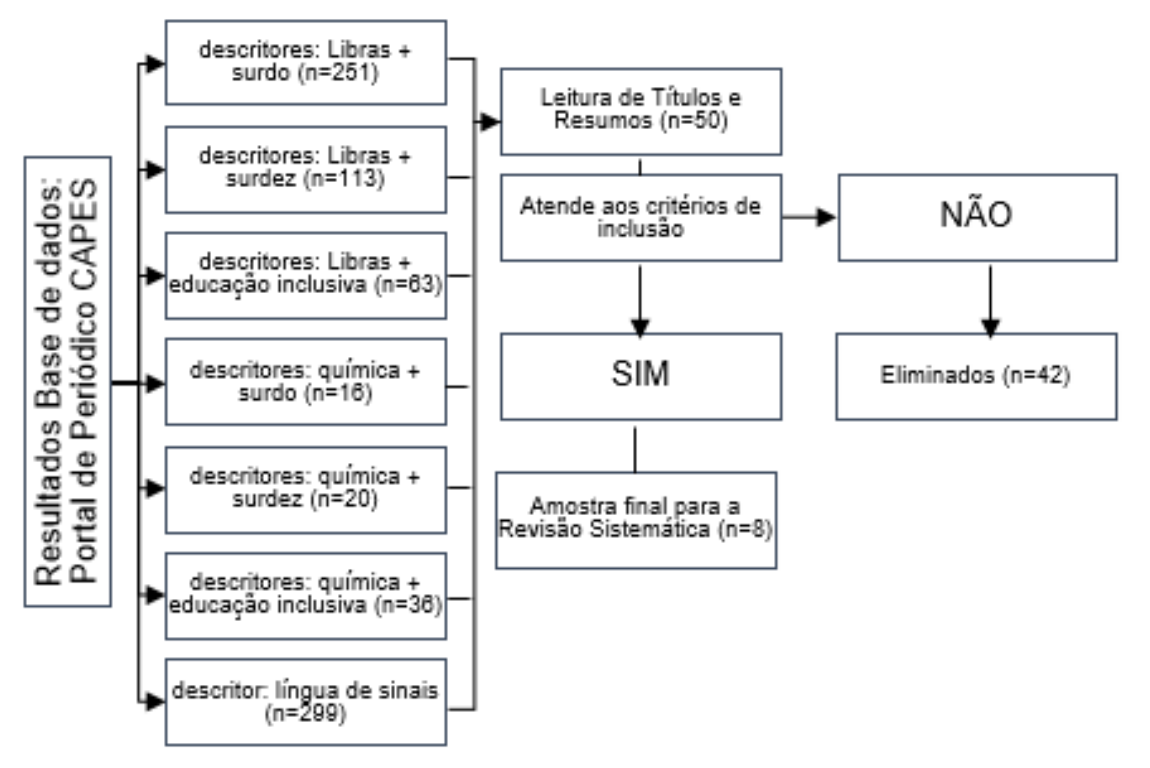

Fonte: Elaboração própria. 
Os trabalhos encontrados na busca foram lidos, analisados (COSTA; ZOLTOWSKI, 2014) e posteriormente elaborou-se um quadro (Quadro 1) para inserção dos dados gerais dos trabalhos tais como: título do estudo, ano de publicação, revista na qual o estudo foi publicada e autores do trabalho, revelando um panorama geral da temática para posterior avaliação crítica dos resultados encontrados.

\section{Resultados e Discussão}

O Quadro 1 contém informações gerais dos trabalhos selecionados, para posterior análise e discussão.

Quadro 1 - Caracterização dos artigos selecionados para a revisão

\begin{tabular}{|c|c|c|c|}
\hline Autores & $\begin{array}{c}\text { Ano de } \\
\text { publicacão }\end{array}$ & $\begin{array}{c}\text { Revista } \\
\text { publicada }\end{array}$ & Título \\
\hline $\begin{array}{l}\text { Retondo e } \\
\text { Silva }\end{array}$ & 2008 & $\begin{array}{l}\text { Química } \\
\text { Nova na } \\
\text { Escola }\end{array}$ & $\begin{array}{l}\text { Ressignificando a formação de professores de } \\
\text { química para a educação especial e inclusiva: } \\
\text { Uma história de parcerias }\end{array}$ \\
\hline $\begin{array}{l}\text { Sousa e } \\
\text { Silveira }\end{array}$ & 2011 & $\begin{array}{l}\text { Química } \\
\text { Nova na } \\
\text { Escola }\end{array}$ & $\begin{array}{l}\text { Terminologias químicas em libras: a utilização de } \\
\text { sinais na aprendizagem de alunos surdos }\end{array}$ \\
\hline $\begin{array}{l}\text { Pereira, Benite } \\
\text { e Benite }\end{array}$ & 2011 & $\begin{array}{l}\text { Química } \\
\text { Nova na } \\
\text { Escola }\end{array}$ & $\begin{array}{l}\text { Aula de química e surdez: Sobre interações } \\
\text { pedagógicas mediadas pela visão }\end{array}$ \\
\hline $\begin{array}{l}\text { Ferreira, } \\
\text { Nascimento e } \\
\text { Pitanga }\end{array}$ & 2014 & $\begin{array}{l}\text { Química } \\
\text { Nova na } \\
\text { Escola }\end{array}$ & $\begin{array}{l}\text { Dez anos da lei da Libras: Um conspecto dos } \\
\text { estudos publicados nos últimos } 10 \text { anos nos } \\
\text { anais das reuniões da Sociedade Brasileira de } \\
\text { Química }\end{array}$ \\
\hline $\begin{array}{l}\text { Stadler, } \\
\text { Filietaz e } \\
\text { Hussein }\end{array}$ & 2014 & $\begin{array}{l}\text { Revista } \\
\text { Tecné, } \\
\text { Episteme } \\
\text { y Didaxis: } \\
\text { TED }\end{array}$ & $\begin{array}{l}\text { Investigação de terminologias científicas de } \\
\text { química em língua brasileira de sinais em escola } \\
\text { bilíngue de Curitiba, Brasil }\end{array}$ \\
\hline $\begin{array}{l}\text { Vilela-Ribeiro, } \\
\text { Costa, Rocha, } \\
\text { Borges, Vaz, } \\
\text { Benite e Lima- } \\
\text { Ribeiro }\end{array}$ & 2014 & $\begin{array}{l}\text { Revista } \\
\text { Tecné, } \\
\text { Episteme } \\
\text { y Didaxis: } \\
\text { TED }\end{array}$ & $\begin{array}{l}\text { O ensino de química para alunos surdos e } \\
\text { ouvintes: utilizando a experimentação como } \\
\text { estratégia didática para o ensino de Cinética } \\
\text { Química }\end{array}$ \\
\hline Bastos & 2016 & $\begin{array}{l}\text { Journal of } \\
\text { Research } \\
\text { in Special } \\
\text { Education } \\
\text { al Needs }\end{array}$ & $\begin{array}{l}\text { Proposição de recursos pedagógicos acessíveis: } \\
\text { O ensino de química e a tabela periódica }\end{array}$ \\
\hline $\begin{array}{l}\text { Gomes, } \\
\text { Abrantes e } \\
\text { Valadares }\end{array}$ & 2016 & $\begin{array}{l}\text { Revista } \\
\text { ELO- } \\
\text { Diálogos } \\
\text { em } \\
\text { Extensão }\end{array}$ & $\begin{array}{l}\text { (Re)desenhando o trabalho com/para surdos em } \\
\text { Viçosa:contribuições do projeto Surdo Cidadão } \\
\text { da UFV }\end{array}$ \\
\hline
\end{tabular}

Fonte: Elaboração própria 
http://dx.doi.org/10.5902/1984686X31242

Os trabalhos encontrados puderam ser categorizados pelas temáticas mais frequentes como: adaptação de material didático, estratégia metodológica, criação de léxico e pesquisa bibliográfica. A seleção final dos trabalhos resultou em apenas 8 publicações ao longo dos 15 anos da Lei da Libras, indicando como ainda são recentes e escassos os estudos que propõe temática envolvendo o ensino de química para alunos surdos.

Com relação ao que os estudos propuseram, o trabalho "Dez anos da lei da Libras: Um conspecto dos estudos publicados nos últimos 10 anos nos anais das reuniões da Sociedade Brasileira de Química" apresentou uma pesquisa bibliográfica sobre ensino de química e surdez (FERREIRA; NASCIMENTO; PITANGA, 2014). A proposta do artigo visou a busca no endereço eletrônico dos anais das Reuniões Anuais da Sociedade Brasileira de Química (RASBQ) por resumos apresentados num intervalo de 10 anos a partir da publicação da Lei da Libras. Esta resultou em 11 resumos com a temática proposta, indicando a necessidade de mais estudos em áreas específicas. O mesmo foi notado pela presente revisão sistemática, pois também foram encontrados poucos artigos publicados que abordam o ensino de química e a surdez. Pode-se dizer que estes resumos apresentados no congresso apontam expansão e interesse em pesquisar e compreender a educação especial para surdos no campo da química, possibilitando avanços e novos estudos na área, entretanto, mostra também a ausência de profissionais da área da química e demais ciências naturais com formação para pesquisar/atuar na interface Química/Educação Especial.

Dois trabalhos analisados realizaram seus estudos a partir da elaboração ou adaptação de material didático (RETONDO; SILVA, 2008; BASTOS, 2016). Em ambos os casos, o estudo não propôs apenas o direcionamento para a área da surdez na elaboração do material, mas para diversas deficiências. O tipo de pesquisa desenvolvida em ambos foi a pesquisa participante e, embora os trabalhos apresentem as etapas envolvidas no processo de elaboração/ adaptação do material, nenhum deles apresentou como foi realizada a aplicação do material ao público pretendido.

O estudo "Ressignificando a formação de professores de química para a educação especial e inclusiva: Uma história de parcerias", de Retondo e Silva (2008), consistiu em apresentar aos alunos de um curso de Licenciatura em Química, durante uma disciplina que envolvia estágio curricular supervisionado, estudos e palestras com a temática Educação Especial, seguida da observação do cotidiano de instituições e escolas com estes alunos. Posteriormente sugeriu-se aos licenciandos a elaboração de material didático 
http://dx.doi.org/10.5902/1984686X31242

e construção de relatório para a disciplina. $O$ resultado apontado pelas autoras foi possibilitar aos licenciandos uma reflexão sobre a prática docente e a inclusão de alunos com deficiência. O estudo de Bastos (2016) "Proposição de recursos pedagógicos acessíveis: O ensino de química e a tabela periódica" discutiu os procedimentos a serem adotados e cuidados necessários na construção e adequação de recursos pedagógicos para o ensino de alunos público alvo da educação especial. Foram apresentadas etapas de análise para a elaboração de material adaptado, constando os pontos mais relevantes estudados no processo envolvendo as temáticas do desenho universal da aprendizagem, da neurociência, da educação especial e das tecnologias assistivas que foram desenvolvidas para o público do $1^{\circ}$ ano do Ensino Médio. O resultado foi a elaboração de uma tabela periódica cujas características possibilitaram aos alunos com deficiência a compreensão dos temas químicos, promovendo a inclusão de alunos deficientes numa sala de aula regular.

Nos dois trabalhos supracitados, pode-se dizer que há docentes universitários preocupados com a formação dos licenciandos e com os desafios da inclusão de deficientes numa sala de aula regular, trazendo esta realidade aos alunos por meio da adaptação de materiais para o público surdo, o que é muito relevante. Não se pode afirmar que apenas a adaptação de material garante o ensino e aprendizagem do aluno, pois é necessário que este aluno consiga fazer uma relação entre os sentidos e conceitos a serem aprendidos, e que este faça parte do cotidiano do aluno, todavia nota-se um movimento da área já na formação de recursos humanos, neste caso dos docentes, para o trabalho junto ao público alvo da educação especial. Vale ressaltar a orientação do Decreto quanto à garantia da educação bilíngue para alunos surdos; "[...] Deve ser proporcionado aos professores acesso à literatura e informações sobre a especificidade linguística do aluno surdo" (BRASIL, 2005, s/p.), bem como apoiar e orientar os docentes quanto a diferentes formas de avaliar o aluno, disponibilizar tecnologias e outros recursos didáticos para este ensino diferenciado.

Outros dois trabalhos apresentaram estudos de caso envolvendo a elaboração de léxico em Libras específico para conteúdos de Química, partindo da análise de dicionários de Libras para tal (SOUSA; SILVEIRA, 2011; STADLER; FILIETAZ; HUSSEIN, 2014). Dentre os oito estudos selecionados, apenas o trabalho de Stadler, Filietaz e Hussein (2014) foi realizado numa escola bilíngue. As escolas com perspectivas bilíngues de trabalho consideram a Libras como primeira língua do surdo, enquanto a língua Portuguesa 
http://dx.doi.org/10.5902/1984686X31242

(escrita) é tida como a segunda língua, entretanto, para esta modalidade são necessários profissionais capacitados em ambas línguas, além da disciplina específica para lecionar os conteúdos aos alunos e ainda há poucos professores habilitados para esta modalidade (LACERDA et al, 2016). Outro aspecto que merece destaque diz respeito à criação de léxico específico para conteúdos da Química. Conforme exposto anteriormente (VIGOSTKI, 1991), para que o sujeito tenha possibilidades de acesso ao conhecimento científico faz-se necessário que os conceitos sejam apresentados em sua língua (no caso a Libras). Assim, iniciativas que visem a criação e ampliação do léxico em diferentes áreas de conhecimento são de grande relevância, pois visam minimizar a barreira linguística em sala de aula e proporcionar igualdade de condições no acesso ao conteúdo.

No trabalho "Terminologias químicas em libras: a utilização de sinais na aprendizagem de alunos surdos" Sousa e Silveira (2011) identificaram as dificuldades de interação com os alunos surdos e desconhecimento da Libras pelos professores de química. Verificou-se também a falta de léxico específico apontado pelos Tradutores e Intérpretes de Libras/Língua Portuguesa mediante a realização de entrevistas com estes profissionais, seguida de uma busca por termos químicos em um dicionário de Libras e da sugestão da criação de termos importantes para as aulas, mas ainda inexistentes, pelo grupo de TILS com o auxílio dos professores. O objetivo pretendido pelos autores foi compreender como professores ensinam conceitos químicos e como se dá a apropriação e utilização de termos químicos em Libras para aprendizagem de alunos surdos.

O trabalho "Investigação de terminologias científicas de química em língua brasileira de sinais em escola bilíngue de Curitiba, Brasil” de Stadler, Filietaz e Hussein (2014) foi bastante semelhante, entretanto, os professores participantes eram bilíngues. TILS e professores responderam a questionários e analisaram três dicionários de Libras buscando termos químicos com o objetivo de investigar como é composta a sinalização, em Libras, de termos específicos dos conteúdos de química, no contexto de uma escola bilíngue. Diante da inexistência de alguns termos, foi solicitado a um professor bilíngue que sinalizasse alguns termos químicos não formalizados baseado em sua prática docente, discutindo-se ainda a importância da criação e validação de sinais pela comunidade surda. Ambos os trabalhos indicaram a escassez de léxico específico e sugeriram que a criação de sinais dentro de grupos pode facilitar a compreensão e interpretação de conceitos específicos. 
http://dx.doi.org/10.5902/1984686X31242

Considerando este último aspecto, para Bakhtin (2006) o signo é ideológico e vinculado à condição social do indivíduo, enquanto a significação é dependente do contexto. Portanto, esta relação signo e significação está relacionada ao domínio que o indivíduo possui da comunicação e da língua. Essa ideia pode ser transposta para o contexto da Libras e do Ensino de Química, de modo que a língua de sinais é usada pelos surdos refletindo sua condição de comunicação e o círculo social no qual o indivíduo surdo está inserido; e o ensino, de modo geral, é elaborado para a condição de alunos ouvintes, evidenciando a relação de domínio entre as línguas, o que suprime a importância da língua de sinais.

[...] A classe dominante tende a conferir ao signo ideológico um caráter intangível e acima das diferenças de classe, a fim de abafar ou de ocultar a luta dos índices sociais de valor que aí se trava, a fim de tornar o signo monovalente (BAKHTIN, 2006, p. 46).

Assim, pode-se falar da importância da Libras e da criação de léxico específico para que o aluno surdo tenha condições de estabelecer uma relação entre signo e significação entre a Libras e a Química, promovendo o ensino e aprendizagem do aluno, bem como oferecendo condições para que este torne o conteúdo aprendido significativo para si. A criação de sinais é possível mediante parcerias realizadas em sala de aula com professores, intérpretes e comunidade surda e a participação dos surdos nas diversas áreas de conhecimento.

Pensando na importância da educação para o indivíduo, há de se notar que a maioria dos surdos está inserida na educação em escolas regulares, pois as experiências em escolas bilíngues ainda são pouco frequentes. Entretanto, nas escolas regulares, os conteúdos ainda são direcionados exclusivamente aos alunos ouvintes "A escola, em geral, está presa ao texto didático como caminho único para a apresentação de conceitos [...]" (LACERDA, SANTOS, CAETANO, 2014, p. 188) e o currículo é planejado na língua portuguesa como L1, dificultando o ensino e aprendizagem do aluno surdo - mesmo que haja presença do intérprete de Libras. Na escola bilíngue, todo o currículo é planejado para o aluno surdo, tendo a Libras como L1, valorizando a cultura surda - ou seja, assegurando o direito a educação da mesma forma que para os alunos não surdos. Assim, é importante que a aula atenda às necessidades do aluno surdo, com conceitos acessíveis, a partir de estratégias visuais que favoreçam estes alunos, tais como: mapas conceituais, imagens, vídeos (LACERDA, SANTOS, CAETANO, 2014). 
http://dx.doi.org/10.5902/1984686X31242

Dentre os oito trabalhos selecionados, três deles apresentaram diferentes estratégias metodológicas para auxiliar o surdo na aprendizagem dos conteúdos de química. Pereira, Benite e Benite (2011) com o objetivo de estabelecer o diálogo com a cultura surda na aula de química, apresentaram em sua pesquisa, "Aula de química e surdez: Sobre interações pedagógicas mediadas pela visão", uma proposta metodológica de ensino de Modelos Atômicos para que os alunos surdos tivessem acesso ao conteúdo da aula de química pelo campo visual (cartazes e histórias em quadrinhos), partindo das dificuldades relatadas em entrevistas e questionários respondidas por intérpretes e alunos. Já Vilela-Ribeiro et al (2014), em "O ensino de química para alunos surdos e ouvintes: utilizando a experimentação como estratégia didática para o ensino de Cinética Química", abordaram o conteúdo de Cinética Química através de aulas experimentais para tornar os conceitos mais visuais, objetivando elaborar e analisar esta estratégia didática para aplicação em salas de aulas com alunos surdos e ouvintes. Os dois trabalhos (PEREIRA; BENITE; BENITE, 2011; VILELA-RIBEIRO et al, 2014) também avaliaram os conceitos trabalhados em aula solicitando que os alunos fizessem desenhos com o intuito de verificar a elaboração e significação dos conceitos relacionados à temática apresentada.

No artigo "(Re)desenhando o trabalho com/para surdos em Viçosa: contribuições do projeto Surdo Cidadão da UFV", Gomes, Abrantes e Valadares (2016) orientaram e promoveram um Projeto na Universidade Federal de Viçosa (UFV) que realizou minicursos de Libras, palestras e oficinas para surdos e ouvintes de uma comunidade, com o objetivo de desenvolver e apoiar atividades que visassem: divulgar, difundir, ensinar e conscientizar sobre a importância da Língua Brasileira de Sinais, bem como auxiliar na apropriação de conhecimento científico de Química e Matemática. Nos três trabalhos (PEREIRA; BENITE; BENITE, 2011; VILELA-RIBEIRO et al, 2014; GOMES; ABRANTES; VALADARES, 2016) os resultados obtidos foram bastante semelhantes, e evidenciaram a importância da elaboração de estratégias de ensino visuais (imagens, experimentação) para possibilitar a participação e processos de aprendizado que favorecessem a compreensão pelos alunos surdos.

Campello (2008) aborda a importância da visualidade para alunos surdos; em sua pesquisa a autora destaca que explorar a visualidade faz-se primordial nos processos de ensino, visto que o surdo tem acesso aos conhecimentos através dos olhos. A autora referese ao termo "semiótica imagética", reconhecendo o uso de imagens como signo, como elemento simbólico - para além das construções, traduções e da própria língua de sinais: 
http://dx.doi.org/10.5902/1984686X31242

A técnica dos aspectos da visualidade na educação de Surdos exige, sobretudo, o uso da imagem, captando em todas as suas essências que nos rodeiam, traduzindo todas as formas de interpretações e do seu modo de ver, de forma subjetiva e objetiva. Não é, simplesmente, usar a língua de sinais brasileira, como uma língua simples, mecanizada, e sim, muito mais. Exige perceber todos os elementos que rodeiam os sujeitos Surdos enquanto signos visuais (CAMPELLO, 2008, p. 136).

Trata-se de um campo importante e ainda pouco explorado nos estudos. A presença do TILS garante a acessibilidade, mas não o aprendizado; deste modo, cabe ao professor desenvolver/elaborar estratégias que envolvem o campo visual e o pensamento imagético para que o aluno compreenda os inúmeros conceitos que circulam em sala de aula, possibilitando ao surdo a compreensão do conteúdo explanado na área da química.

\section{Considerações Finais}

Apesar das leis que asseguram a inclusão educacional de alunos surdos em salas de aula regulares, pode-se afirmar que há uma escassez de profissionais com conhecimento de Libras ou com formação para lecionar para estes alunos, visto que a obrigatoriedade da disciplina de Libras aos cursos de Licenciatura teve início em 2005, com a publicação do Decreto 5.626 (BRASIL, 2005). Também é notória a importância das escolas bilíngues na formação básica dos alunos surdos, considerando que os alunos nesta modalidade educacional têm acesso ao conteúdo em Libras - mas poucas são as experiências com escolas bilíngues para surdos no Brasil.

Esta revisão pôde nos apresentar o que tem sido realizado no ensino básico na disciplina de química para promover o acesso ao aluno surdo em suas aulas e os aspectos positivos desta inclusão. Assim, estratégias que estabeleceram parcerias com o TILS para a "convenção" de sinais específicos para o conteúdo da aula de química, aulas experimentais e uso da visualidade nas aulas favorecem o ensino e aprendizagem de todos em sala de aula, facilitando a comunicação e a aprendizagem de determinado conteúdo. Entretanto, a criação e validação de um sinal específico é mais criteriosa.

O fato de haver pouquíssimos artigos que apresentam a interface Ensino de Química e Surdez, demonstra que as pesquisas não têm dado a atenção merecida a um conteúdo de tanta relevância na formação de alunos surdos. As experiências de ensino de Química nas escolas ditas inclusivas carecem de mais discussão sobre os possíveis modos de realizar este ensino, para que seja acessível e compreensível ao aluno surdo, assim como as demais disciplinas. Nota-se que a inclusão, não só de surdos, mas de modo geral, 
http://dx.doi.org/10.5902/1984686X31242

também tem sido tema de disciplinas de cursos de Licenciatura em Química com a proposta de melhor preparar os licenciandos em sua formação.

Espera-se que o estudo apresentado possa contribuir com a interface Ensino de Química e Surdez, mostrando propostas realizadas em outras instituições de ensino, parcerias estabelecidas no processo de ensino e aprendizagem, bem como possíveis lacunas para estudos posteriores.

\section{Referências}

BAKHTIN, Mikhail. Marxismo e Filosofia da Linguagem. 12 $2^{\mathrm{a}}$ ed. HUCITEC, 2006. $193 \mathrm{p.}$

BASTOS, Amélia Rota Borges. Proposição de recursos pedagógicos acessíveis: - ensino de química e a tabela periódica. Journal of Research in Special Educational Needs, v. 16, n. 1, 2016, p. 923-927.

BIZZO, Nélio. Ciências: fácil ou difícil? 2ª edição. Editora Ática, 2002. 144 p.

BRASIL. Decreto № 5.626 de 22 de dezembro de 2005. Regulamenta a Lei no 10.436 , de 24 de abril de 2002, que dispõe sobre a Língua Brasileira de Sinais - LIBRAS, e o art. 18 da Lei $n^{0}$ 10.098, de 19 de dezembro de 2000. Diário Oficial [da] República Federativa do Brasil, Brasília, 23 de dezembro de 2005.

BRASIL. Lei nำ 10.436 de 24 de abril de 2002. Dispõe sobre a Língua Brasileira de Sinais e dá outras providências. Diário Oficial [da] República Federativa do Brasil, Brasília, 25 de abril de 2002.

BRASIL. Lei $n^{\circ} 12.319$ de $1^{\circ}$ de setembro de 2010. Regulamenta a profissão de Tradutor e Intérprete da Língua Brasileira de Sinais - LIBRAS. Diário Oficial [da] República Federativa do Brasil, Brasília, 2 de setembro de 2010.

BRASIL. Secretaria de Educação Básica. Ministério da Educação. Base Nacional Comum Curricular. Brasília, 2016. Disponível em: $<$ http://historiadabncc.mec.gov.br/documentos/bncc-2versao.revista.pdf $>$ Acesso em 11 jun. 2018.

BRASIL. Secretaria de Educação Básica. Ministério da Educação. Orientações Curriculares para o Ensino Médio - Ciências da Natureza, Matemática e suas Tecnologias. Brasília, 2006. Disponível em: $<$ http://portal.mec.gov.br/seb/arquivos/pdf/book volume 02 internet.pdf $>$ Acesso em 13 jun. 2018.

CAETANO, Juliana Fonseca; LACERDA, Cristina Broglia Feitosa. LIBRAS no currículo de cursos de licenciatura: estudando o caso das Ciências Biológicas. In: LACERDA, Cristina Broglia Feitosa; SANTOS, Lara Ferreira (Orgs). Tenho um aluno 
http://dx.doi.org/10.5902/1984686X31242

surdo, e agora? Introdução à LIBRAS e educação de surdos. São Carlos: EdUFSCar, 2014. cap. 13, p. 219-236.

CAMPELLO, Ana Regina e Souza. Aspectos da visualidade na educação de surdos. Florianópolis: UFSC, 2008, 245 p. (Tese- Doutorado em Educação).

CAMPOS, Mariana de Lima Isaac Leandro. Educação Inclusiva Para Surdos e as Políticas Vigentes. In: LACERDA, Cristina Broglia Feitosa; SANTOS, Lara Ferreira (Org). Tenho um aluno surdo, e agora? Introdução à LIBRAS e educação de surdos. São Carlos: EdUFSCar, 2014. cap. 3, p. 37-61.

CHASSOT, Attico Inácio. Catalisando transformações na educação. $1^{\underline{a}}$ ed. Editora UNIJUÍ, 1993. 174 p.

COSTA, Angelo Brandelli; ZOLTOWSKI, Ana Paula Couto. Como escrever um artigo de revisão sistemática. In: KOLLER, Sílvia H.; COUTO, Maria Clara P. de Paula; HOHENDORFF, Jean Von. Manual de Produção Científica. 1a ed. Porto Alegre, RS: Penso Editora LTDA, 2014, p.55-70.

FERREIRA, Wendel Menezes; NASCIMENTO, Sandra Patricia de Faria; PITANGA, Angelo Francklin. Dez Anos da Lei da LIBRAS: Um Conspecto dos Estudos Publicados nos Últimos 10 Anos nos Anais das Reuniões da Sociedade Brasileira de Química. Química Nova na Escola, v. 36, n. 3, São Paulo, ago. 2014, p. $185-193$.

GALVÃO, Cristina Maria; SAWADA, Namie Okino; TREVIZAN, Maria Auxiliadora. Revisão sistemática: recurso que proporciona a incorporação das evidências na prática da enfermagem. Revista Latino-Americana de Enfermagem, v.12, n.3, Ribeirão Preto, maio/jun. 2004, p.549-556.

GIL, Antônio Carlos. Métodos e Técnicas de Pesquisa Social. 6ª ed. São Paulo: Editora Atlas S.A., 2008. 200 p.

GOMES, Eduardo Andrade; ABRANTES, Ana Paula; VALADARES, Cristiane Botelho. (Re)desenhando o trabalho com/para surdos em Viçosa: contribuições do projeto Surdo Cidadão da UFV. Revista ELO - Diálogos em Extensão, v. 05, n. 03, Viçosa, dez. 2016, p. 62-67.

LACERDA, Cristina Broglia Feitosa. A inclusão escolar de alunos surdos: o que dizem alunos, professores e intérpretes sobre esta experiência. Caderno Cedes, v. 26, n. 69, Campinas, maio/ago. 2006, p. 163-184.

LACERDA, Cristina Broglia Feitosa; SANTOS, Lara Ferreira; CAETANO, Juliana Fonseca. Estratégias metodológicas para o ensino de alunos surdos. In: LACERDA, Cristina Broglia Feitosa; SANTOS, Lara Ferreira (Org). Tenho um aluno surdo, e agora? Introdução à LIBRAS e educação de surdos. São Carlos: EdUFSCar, 2014. cap. 11 , p. 185-200. 
LACERDA, Cristina Broglia Feitosa; GURGEL, Taís Margutti do Amaral. Perfil de tradutores-intérpretes de Libras (TILS) que atuam no ensino superior no Brasil. Revista Brasileira de Educação Especial, v. 17, n. 3, Marília, set./dez. 2011, p. 481496.

LACERDA, Cristina Broglia Feitosa de; SANTOS, Lara Ferreira dos; MARTINS, Vanessa Regina de Oliveira. (orgs). Escola e Diferença: caminhos para educação bilíngue de surdos. São Carlos: EDUFSCar, 2016,

LODI, Ana Claudia Balieiro. Educação bilíngue para surdos e inclusão segundo a Política Nacional de Educação Especial e o Decreto no 5.626/05. Educação e Pesquisa, v. 39, n. 1, São Paulo, jan./mar. 2013, p. 49-63.

LODI, Ana Claudia Balieiro. Plurilingüismo e surdez: uma leitura bakhtiniana da história da educação dos surdos. Educação e Pesquisa, v. 31, n. 3, São Paulo, set./dez. 2005, p. 409-424.

MORAES, Roque; GALIAZZI, Maria do Carmo. Análise textual discursiva: processo reconstrutivo de múltiplas faces. Ciência \& Educação, v. 12, n. 1, Bauru, jan./abr. 2006, p. 117-128.

MORTIMER, Eduardo Fleury. Construtivismo, mudança conceitual e ensino de ciências: para onde vamos? Investigações em Ensino de Ciências, v.1, n.1, Porto Alegre, mar. 1996, p. 20-39.

NOVAES, Rosecléa Gotardo; TRUGILLO, Edneuza Alves. O aluno surdo no contexto do ensino regular. Revista Eventos Pedagógicos, v. 2, n. 2, Sinop, ago./dez. 2011, p. 210-219.

OLIVEIRA, Janine Soares; STUMPF, Marianne Rossi. Desenvolvimento de glossário de Sinais Acadêmicos em ambiente virtual de aprendizagem do curso Letras-Libras. Informática na Educação: teoria \& prática, v. 16, n. 2, Porto Alegre, jul./dez. 2013, p. 217-228.

PEREIRA, Rosamaria Reo. et al. Inclusão de estudantes com deficiência no ensino superior: uma revisão sistemática. Revista Educação Especial, v. 29, n. 54, Santa Maria, jan./abr. 2016, p. 147-160.

PEREIRA, Lidiane de L. S.; BENITE, Claudio R. Machado; BENITE, Anna M. Canavarro. Aula de Química e Surdez: sobre Interações Pedagógicas Mediadas pela Visão. Química nova na escola, v. 33, n. 1, São Paulo, fev. 2011, p. 47-56.

RETONDO, Carolina Godinho; SILVA, Glaucia Maria. Ressignificando a Formação de Professores de Química para a Educação Especial e Inclusiva: Uma História de Parcerias. Química nova na escola, n. 30, São Paulo, nov. 2008, p. 27-33.

SALES, Elielson Ribeiro; PENTEADO, Miriam Godoy; MOURA, Amanda Queiroz. A Negociação de Sinais em Libras como Possibilidade de Ensino e de 
http://dx.doi.org/10.5902/1984686X31242

Aprendizagem de Geometria. Bolema, v. 29, n. 53, Rio Claro, dez. 2015, p. 12681286.

SANTOS, L. F. dos. 0 instrutor surdo em uma escola inclusiva bilíngue: sua atuação junto aos alunos surdos no espaço da Oficina de Língua Brasileira de Sinais. 2007. Dissertação (Mestrado em Educação) - Universidade Metodista de Piracicaba, Piracicaba, 2007.

SANTOS, Lara Ferreira; LACERDA, Cristina Broglia Feitosa. Atuação do intérprete educacional: parceria com professores e autoria. Cadernos de Tradução, v. 35, no especial 2, Florianópolis, jul./dez. 2015, p. 505-533.

SKLIAR, Carlos. Bilinguismo e biculturalismo. Uma análise sobre as narrativas tradicionais na educação dos surdos. Revista Brasileira de Educação, s/ v., n. 8, Rio de Janeiro, maio/jun./jul./ago. 1998, p. 44-57.

SOUSA, Sinval Fernandes; SILVEIRA, Hélder Eterno. Terminologias Químicas em Libras: A Utilização de Sinais na Aprendizagem de Alunos Surdos. Química nova na escola, v. 33, n. 1, São Paulo, fev. 2011, p. 37-46.

STADLER, João Paulo; FILIETAZ, Marta Rejane Proença; HUSSEIN, Fabiana R. G. e Silva. Investigação de Terminologias Científicas de Química em Língua Brasileira de Sinais em Escola Bilíngue de Curitiba, Brasil. Revista Tecné, Episteme y Didaxis: TED, Número Extraordinario, Bogotá, out. 2014, p. 234-241.

VIGOTSKI, Lev Semenovitch. A Formação Social da Mente. $4^{\underline{a}}$ ed. Livraria Martins Fontes Editora Ltda., São Paulo, 1991.90 p.

VILELA-RIBEIRO, Eveline Borges. et al. O ensino de química para alunos surdos e ouvintes: utilizando a experimentação como estratégia didática para o ensino de Cinética Química. Revista Tecné, Episteme y Didaxis: TED, Número Extraordinario, Bogotá, out. 2014, p. 808-816.

\section{Correspondência}

Greice de Souza Vertuan - Universidade Federal de São Carlos, Rod. Washington Luiz, s/n. CEP: 13565-905, São Carlos, São Paulo, Brasil.

http://orcid.org/0000-0002-1825-0097

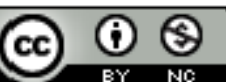

This work is licensed under a Creative Commons Attribution-NonCommercial 4.0 International (CC BY-NC 4.0) 